\title{
Transient Analysis of Quasi Oppositional Based Lightning Search Algorithm Optimized PID Controller in Isolated Small Hydro Power Plant
}

\author{
Shashikant ${ }^{*}$ and Binod Shaw \\ Department of Electrical Engineering, NIT, Raipur, C.G, India. \\ Received January 4, 2018; Accepted March 15, 2018; Published April 24, 2018
}

\begin{abstract}
In this paper, Small Hydro Plant (SHP) of $1.3 \mathrm{MW}$ is simulated with two conventional PID controllers in excitation system and governor to enhance the capability to handle the transiency of the generator. Excitation voltage control and turbine speed control are the two basic control schemes, to regulate reactive power or terminal voltage and real power or frequency respectively. The selection parameters of the PID controllers are significant to enhance the performance of the system. Quasi Oppositional Based Lightning Search Algorithm (QOLSA) is validated in this paper to optimize the PID controllers over LSA and PSO. Renewable energy source like SHP is environment friendly and very imperative to meet the vigorously growing load demand. The simulation of the SHP is established in MATLAB/SIMULINK environment. Finally, QOLSA optimized PID controller contributes better control in terminal voltage and power over LSA and PSO algorithms.
\end{abstract}

Keywords: Lightning Search Algorithm (LSA); Quasi Oppositional Based LSA (QOLSA); Small Hydro Power Plant (SHP); Proportional Integral Derivative(PID)

\section{INTRODUCTION}

For last two decades, the load demand of electricity is growing vigorously, due to this, power generation is unable to meet the load demand. In our power system network, most of the power is generated from conventional source of energy. The problem of using conventional sources of energy is: it is costly, creates pollution, and takes time to generate power and the huge requirement of raw materials which are extracted from fossil fuels. Earlier, we were enriched with natural resources and fossil fuels but due to extraction of fossil fuel it may get depleted in the near future. Providently, we have an alternate approach to generate electricity from non-conventional sources of energy. In this paper, an isolated Small Hydro Plant (SHP) is presented to meet the load less than $5 \mathrm{MW}$. SHP has following advantages, which attract the interest of readers and industrialist.

- It is flexible.

- Under heavy load conditions gives supply to the grid.

- Standalone systems in rural areas.

- It is eco-friendly.

G. Baidya [1] has described a brief study about the advantages of SHP, current status of SHP in globe, government policies, and cost of installation \& maintenance. The 
procedure to obtain the accurate governor model to improve the system stability, modeling of hydraulic turbine and their mathematical equations are well portrayed in [2]. Dewangan et. al. [3] enhanced the performance of the SHP by implementing craziness based particle swarm optimization (CRPSO) optimized PID controllers in both excitation and governor of the isolated alternator. Tenorio [4] presented a report on hydraulic governor and turbine model. They had also discussed the components of the various models of hydraulic governor and turbines. Kim and Schaefer [6] discussed the performance of excitation system and suggested the tuning methods for excitation parameter. Parameter for modeling synchronous machine designing is discussed in [7]. Enhancing the performance of the SHP by concerning frequency and terminal voltage has been attempted by many researchers in [8-18] by adopting some intelligent controller and some optimization techniques. Application of some adoptive algorithms in interconnected Hydro-Thermal power system are validated in [19, 20].

This present paper is an endeavor to design a SHP to enhance the terminal voltage and the power transient stability by implementing PID controllers in excitation and governor systems, respectively. The gain parameters of the PID controller have very vital aspects to enhance the performance of the system. Quasi Oppositional Base $\neg \neg \mathrm{d}$ Lightning Search Algorithm (QOLSA) technique is adopted to hunt the best pair of parameters of PID controller to enhance the system performance. Lightning search algorithm (LSA) and particle swarm optimization (PSO) algorithm is adopted to validate the QOLSA technique to tune the PID controller.

\section{SYSTEM DISCRIPTION}

SHP model consists of components like governor, servo motor, hydraulic turbine, salient pole alternator and excitation system. The block diagram of the SHP is illustrated in Figure 1. A DC regulated excitation voltage is enforced to the rotor of synchronous generator to enhance the transient response of the terminal voltage. Figure 2 represents the model of excitation system of the generator. Governor system is implemented to regulate the speed of the turbine. The controller in governor system regulates the valve of the gate of the water turbine to enhance the real power and frequency of the generator. The transfer function block of the governor system is portrayed in Figure 3. Servo motor controls the gate opening of water flow in the turbine. Servo motor action is governed by governor action. The simulation of SHP is done in MATLAB software to study its transient and dynamic response of the generator. Two different optimizing techniques (LSA and QOLSA) were executed to optimize PID controller in governor and excitation system. Each block in simulation is represented as a mathematical modeling of the system which is presented in [3].

The governor system has transient and permanent droop. Transient droop allows rotor to change the speed smoothly according to power demand. Droops generally allow generator to operate parallelly according to their capacity and load sharing. 


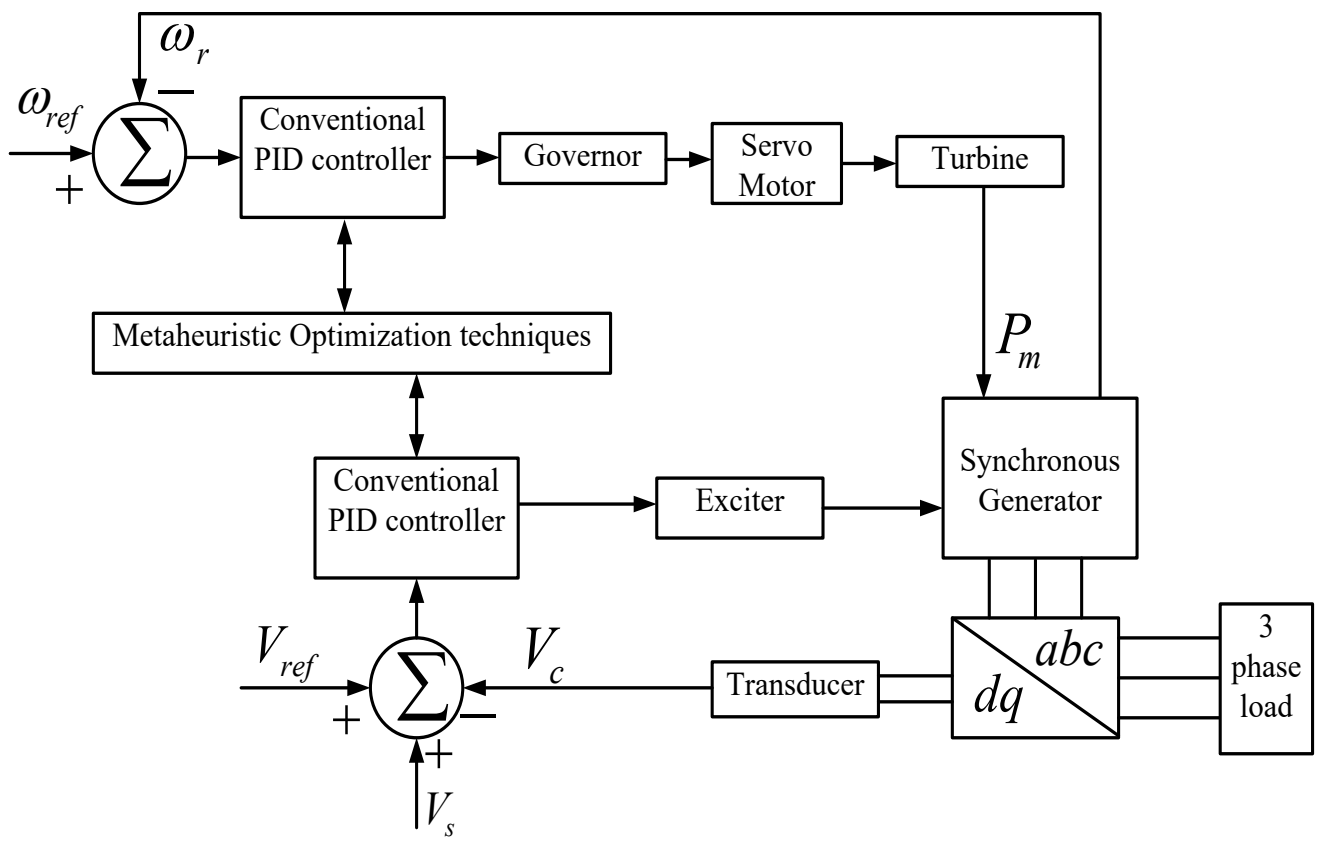

Figure 1. Block diagram of SHP

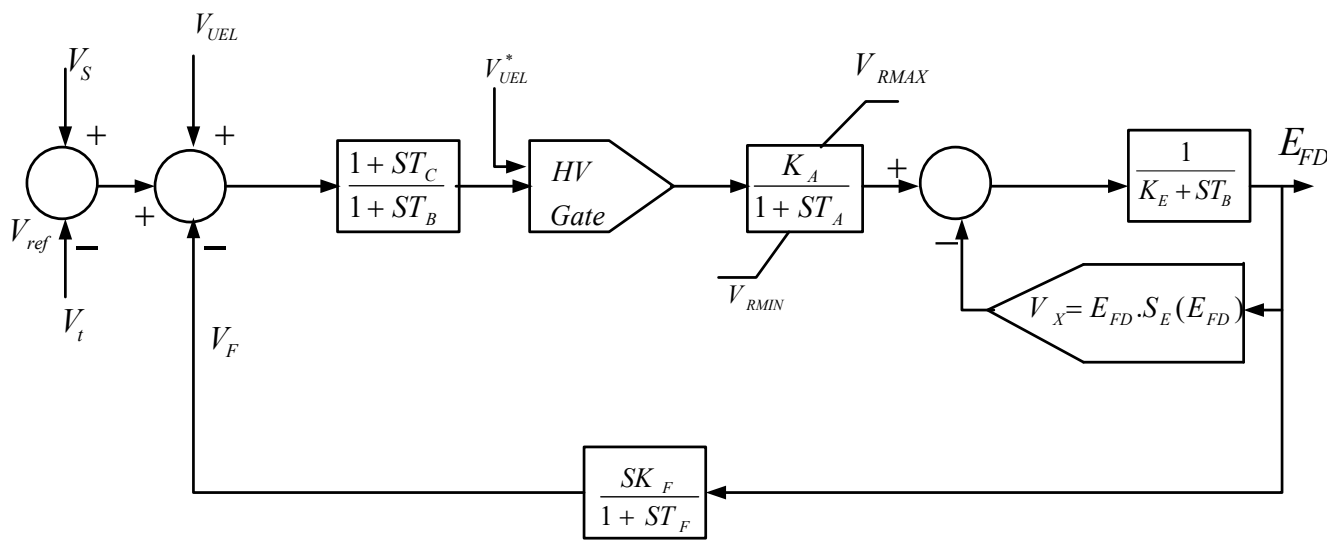

Figure 2. Excitation system transfer function block [5] 


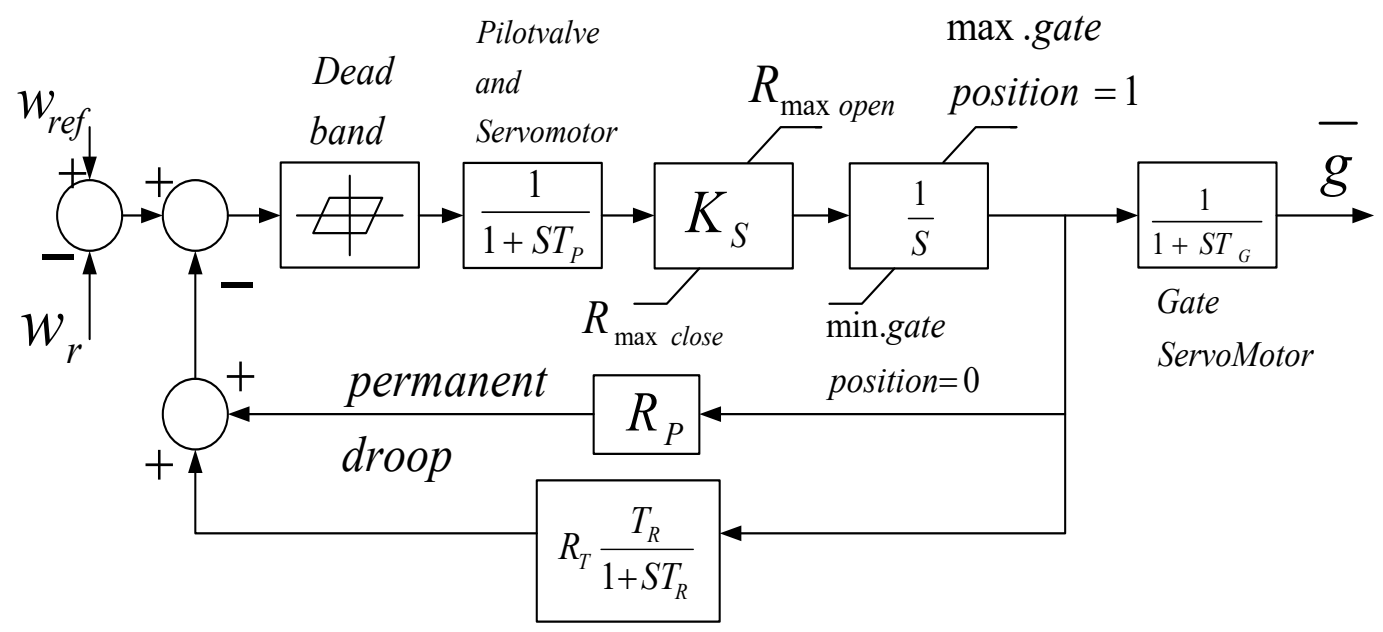

Figure 3. Governor system transfer function block [5]

\section{PID CONTROLLER}

The term PID controller refers to Proportional, Integrator and Derivative controller, which is a feedback control loop mechanism and widely used in industries. It generally calculates an error value $e(t)$ continuously. The error incorporated in the governor system by concerning the difference of desired speed and processed speed. PID controller gives desired result in an optimized way, without overshoot and time delay i.e., its response is fast. Hence, it is applicable for automatic control. The difference between nominal terminal voltage and terminal voltage of generator is considered as an error, fed to the PID controller in the excitation system to control the terminal voltage. The block diagram of PID controller is portrayed in Figure. 4. The mathematical representation of PID controller may be expressed in equation (1).

$u(t)=K_{P} e(t)+K_{I} \int_{0}^{t} e(t) d t+K_{D} \frac{d}{d t} e(t)$

Its equivalent Laplace transform in Laplace domain can be written as equation (2).

$U(s)=K_{P} E(s)+\frac{K_{I}}{s} E(s)+K_{D} s E(s)$

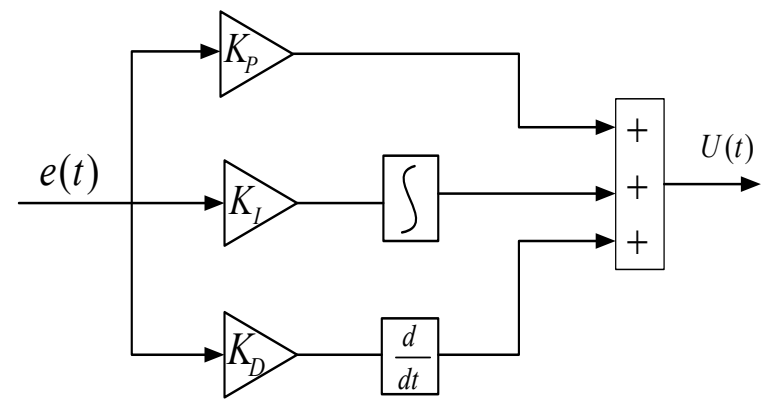

Figure 4. PID controller structure 


\section{QUASI OPPOSITIONAL BASED LIGHTNING SEARCH ALGORITHM (QOLSA)}

This algorithm is inspired by a natural lightning phenomenon which occurs during bad weather condition. Lightning is visible for a few milliseconds (ms). Charge separation takes place within clouds during thunderstorm, and thus forms a strong electric field; due to this its surrounding gets ionized. Hence, more projectiles are generated with the original one. This projectile is being driven by an electric field and causes to form negative corona streamer. This streamer is formed at higher ionization region where attachment probability is less than ionization probability. The streamer or step leader progression is in discrete steps through a channel. A new channel is originated from an old channel forming a long channel whose tip energy is same as the old channel tip energy known as space leader. A current wave is produced when step leader propagates backwards until it connects to old channel. The corona burst out as the wave reaches to the tip of new leader and this process continues. Properties of projectiles and its equation are presented in $[15,16]$. The Oppositional Based Learning (OBL) was introduced by Tizhoosh [17]. Harmony Search (HS) algorithm is modified to enhance the interconnected power system model in [18]. The fundamental purpose of this theory is to improve the accuracy of the result and to stimulate the diversity factor towards the optimal solution by concerning the opposite point of the particle.

Steps involving in QOLSA:

1. Initialize projectile matrix with number of population $\mathrm{N}$ as rows and number of variables $\mathrm{D}$ as columns $\left(\mathrm{P}_{[\mathrm{N} \times \mathrm{D}]}\right)$.

2. Initialize the quasi oppositional vector of same size i.e., the mirror point of the initialized projectile vector $\left(\mathrm{QOP}_{[\mathrm{N} \times \mathrm{D}]}\right)$.

3. The projectile with best functional value is adopted as leader projectile.

4. Set max channel time and energy of leader tips.

5. Randomly generate transition projectiles.

Projectile speed is given in equation (3)

$$
\mathrm{v}_{\mathrm{p}}=\left[1-\left(1 / \sqrt{1-\left(\frac{\mathrm{v}_{\mathrm{O}}}{\mathrm{c}}\right)^{2}}-\mathrm{SF}_{\mathrm{i}} / \mathrm{mc}^{2}\right)^{-2}\right]^{-0.5}
$$

where,

$\mathrm{v}_{\mathrm{p}}$ is current velocity, $\mathrm{v}_{\mathrm{o}}$ is initial velocity, $\mathrm{c}$ is velocity of light, $\mathrm{F}_{\mathrm{i}}$ is constant ionization rate, $\mathrm{m}$ is mass of projectile, $\mathrm{S}$ is path travelled.

The direction at which the projectile is travelling is given in equation (4)

$$
\overline{\mathrm{P}_{i}}=\mathrm{a}+\mathrm{b}-\mathrm{P}_{\mathrm{i}}
$$

where,

$\bar{P}_{i}$ And $\mathrm{P}_{\mathrm{i}}$ is the two different original projectiles, a and $\mathrm{b}$ are boundary limits.

For a successful step leader transition, a channel is formed whose tip energy after several propagation trails is given as a probability density function in equation (5) 


$$
f\left(x^{T}\right)=\left\{\begin{array}{l}
\frac{1}{b-a}, a \leq x^{T} \leq b \\
0, x^{T}<a, x^{T}>b
\end{array}\right.
$$

$\mathrm{X}^{\mathrm{T}}$ is a random number that may provide a solution or the initial tip energy.

Once the channel is formed, the step leader accelerates in the area of old channel to ionize the surroundings. The shape and position of the projectile to form corona streamer is given as a probability density function in equation (6)

$$
f\left(x^{S}\right)=\left\{\begin{array}{l}
\frac{1}{\mu} e^{-x^{S} / \mu} \\
0, x^{S} \leq 0
\end{array}, x^{S} \geq 0\right.
$$

where, $f\left(x^{S}\right)$ represents the probability density function and $\mu$ represents shaping parameter

6. Evaluate performance (projectile energy).

Energy equation is given in (7)

$$
\text { Energy }=2.05-2 \mathrm{e}^{-\frac{5(\mathrm{~T}-\mathrm{t})}{\mathrm{T}}}
$$

where $\mathrm{T}$ is the maximum iteration and $\mathrm{t}$ is the current iteration.

7. Update leader tip energies.

New position and search space are updated when step leader energy is less than projectile energy. The new updated equations $(8,9$, and 10$)$ are given below:

$$
\begin{gathered}
\text { Pi_new }{ }^{\mathrm{S}}=\mathrm{P}_{\mathrm{i}}^{\mathrm{S}} \pm \operatorname{exprand}\left(\mu_{\mathrm{i}}\right) \\
\mathrm{f}\left(\mathrm{x}^{\mathrm{L}}\right)=\frac{1}{\sigma \sqrt{2 \Pi}} \mathrm{e}^{-\left(\mathrm{x}^{\mathrm{L}}-\mu\right)^{2 / 2 \sigma^{2}}} \\
\mathrm{P}_{\text {new }}{ }^{\mathrm{L}}=\mathrm{P}^{\mathrm{L}}+\operatorname{normrand}\left(\mu_{\mathrm{L}}, \sigma_{\mathrm{L}}\right)
\end{gathered}
$$

where $\sigma$ is scale parameter that describes about exploitation ability that decreases exponentially as it travels towards ground.

8. The mirror vector of new projectile vector is obtained from the $P_{\text {new }}$.

9. Update best and worst transition projectiles among both projectile and quasi oppositional projectile.

10. Repeat the steps from 5 to 9 until maximum iteration.

\section{RESULT AND DISCUSSION}

Simulation is carried out on MATLAB 2015a as per the block diagram shown in Figure 1. LSA and QOLSA algorithm are performed in SHP model to determine the gain parameters of the PID controller. Controllers are implemented in both excitation system and governor system to enhance the voltage and power profile. To extract the optimum parameters of the controller, both the algorithms are executed individually with 40 numbers of populations and for 50 iterations. Optimized parameters of PID controller implemented in governor system and excitation system are tabulated in Table 1. Figures 
5 and 6 are the responses of terminal voltage and power of the system for these tunes parameters of the controller, respectively.

Table 1. The gain parameters of PID controller optimized by LSA and QOLSA

\begin{tabular}{|c|c|c|c|}
\hline Controllers & Gain & $\begin{array}{c}\text { Excitation } \\
\text { system }\end{array}$ & $\begin{array}{c}\text { Governor } \\
\text { System }\end{array}$ \\
\hline \multirow{4}{*}{ PSO [3] } & $\mathrm{K}_{\mathrm{P}}$ & 0.2095 & 1.7082 \\
\cline { 2 - 4 } & $\mathrm{K}_{\mathrm{I}}$ & 0.1978 & 1.3472 \\
\cline { 2 - 4 } & $\mathrm{K}_{\mathrm{D}}$ & 0.6202 & 1.2628 \\
\hline \multirow{4}{*}{$\mathrm{LSA}$} & $\mathrm{K}_{\mathrm{P}}$ & 0.2475 & 0.8042 \\
\cline { 2 - 4 } & $\mathrm{K}_{\mathrm{I}}$ & 0.3686 & 0.1529 \\
\cline { 2 - 4 } & $\mathrm{K}_{\mathrm{D}}$ & 0.4807 & 0.4806 \\
\hline \multirow{4}{*}{ QOLSA } & $\mathrm{K}_{\mathrm{P}}$ & 1.6618 & 0.0010 \\
\cline { 2 - 4 } & $\mathrm{K}_{\mathrm{I}}$ & 1.1709 & 0.0010 \\
\cline { 2 - 4 } & $\mathrm{K}_{\mathrm{D}}$ & 2.0000 & 0.7040 \\
\hline
\end{tabular}

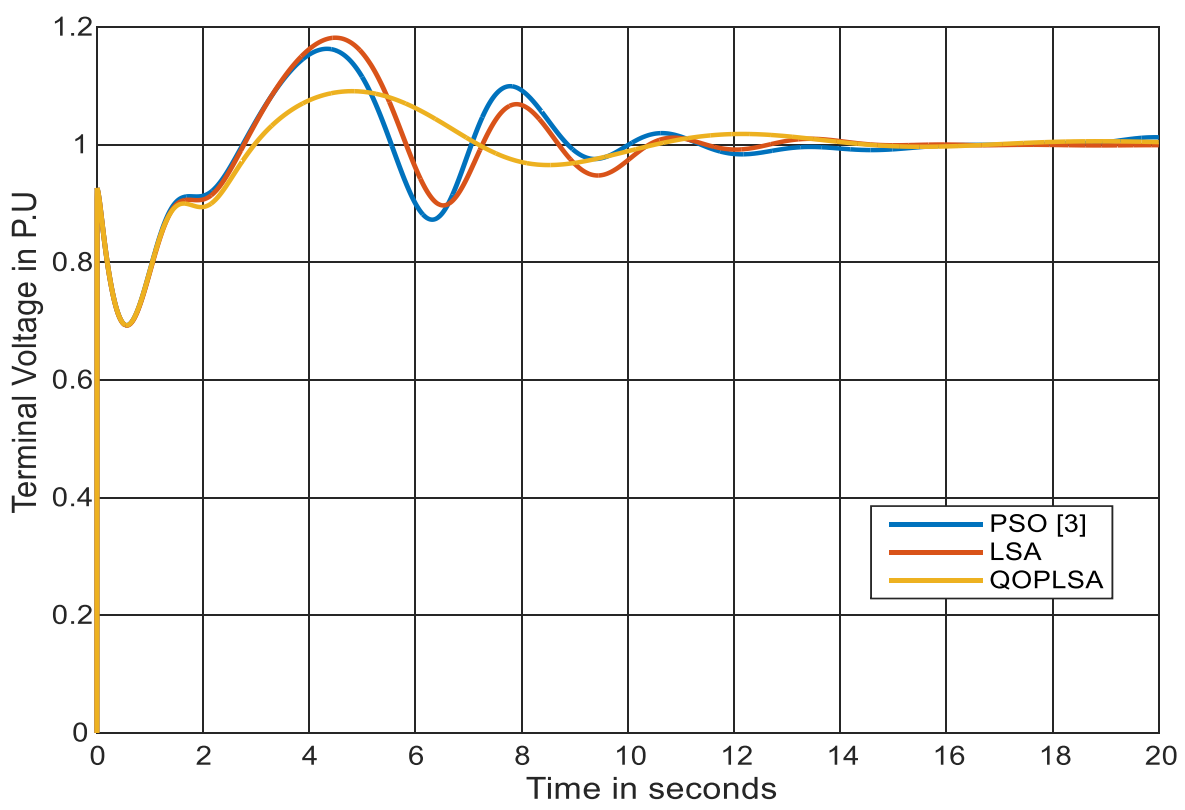

Figure 5. Terminal voltage response 


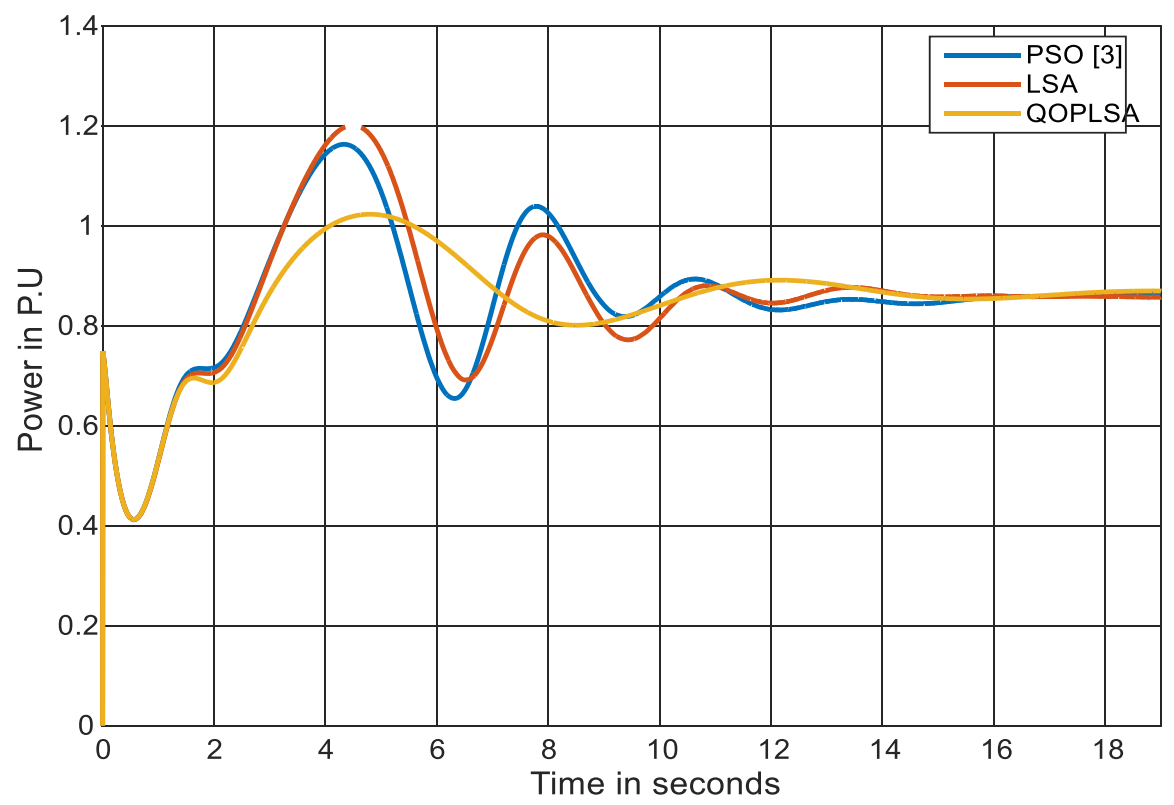

Figure 6. Real power response

Table 2. Peak undershoots ( $\left.U_{s h}\right)$, peak overshoots $\left(\mathrm{O}_{\text {sh }}\right)$ and settling time $\left(T_{s}\right)$ of terminal voltage and power.

\begin{tabular}{|c|l|l|l|}
\hline \multirow{2}{*}{ Controllers } & $\begin{array}{l}\text { Transient } \\
\text { response }\end{array}$ & $\begin{array}{l}\text { Terminal } \\
\text { Voltage } \\
\text { (P.U) }\end{array}$ & $\begin{array}{l}\text { Power } \\
\text { (P.U) }\end{array}$ \\
\hline \multirow{4}{*}{ PSO } & $\mathrm{U}_{\mathrm{sh}}$ & 0.6900 & 0.4126 \\
\cline { 2 - 4 } & $\mathrm{O}_{\mathrm{sh}}$ & 1.1630 & 1.1630 \\
\cline { 2 - 4 } & $\mathrm{T}_{\mathrm{s}}$ & 8.4320 & 8.6350 \\
\hline \multirow{3}{*}{ LSA } & $\mathrm{U}_{\mathrm{sh}}$ & 0.6925 & 0.4119 \\
\cline { 2 - 4 } & $\mathrm{O}_{\mathrm{sh}}$ & 1.1820 & 1.2010 \\
\cline { 2 - 4 } & $\mathrm{T}_{\mathrm{s}}$ & 8.2260 & 8.4900 \\
\hline \multirow{3}{*}{ QOLSA } & $\mathrm{U}_{\mathrm{sh}}$ & 0.6931 & 0.4127 \\
\cline { 2 - 4 } & $\mathrm{O}_{\mathrm{sh}}$ & 1.0910 & 1.023 \\
\cline { 2 - 4 } & $\mathrm{T}_{\mathrm{s}}$ & 6.2080 & 6.7000 \\
\hline
\end{tabular}

The numerical values of Undershoot $\left(\mathrm{U}_{\mathrm{sh}}\right)$, overshoot $\left(\mathrm{O}_{\mathrm{sh}}\right)$ and settling time $\left(\mathrm{T}_{\mathrm{s}}\right)$ of the responses are tabulated in Table 2 to yield a fair contrast between the QOLSA and LSA optimized system. QOLSA optimized system contributes lesser functional value over LSA optimized system.

\section{CONCLUSION}

The proposed work is an approach to validate the QOLSA optimization technique over LSA and PSO [3] to optimize PID controller and to enhance the performance of the system by conceding terminal voltage and power of the generator. The transient response of the system is analyzed by conceding undershoot, overshoot and settling time of the 
response. The undershoot of the system optimized by QOLSA, LSA and PSO are approximately equal. The response of QOLSA optimized PID controller system enhances the system response in terms of overshoot and settling time. The paper is concluded with validating QOLSA optimization technique over LSA and PSO to tune PID controller to yield better transient response of the system.

\section{CONFLICTS OF INTEREST}

The authors declare that there is no conflict of interests regarding the publication of this paper.

\section{REFERENCE}

[1] G. Baidya, "Development of Small Hydro," Himal. Small Hydropower Summit, pp. 34-43, 2006. http://ahec.org.in/links/HSHS/Presentations/Links/Technical\%20Papers/Overview\% 20of\%20SHP\%20Development/Mr\%20G\%20Baidya_Development \%20of\%20SH.p df (accessed on 4/26/2018)

[2] L. N. Hannett, J. W. Feltes, and B. Fardanesh, "Field test to validate hydro-turbine governor model structure and parameters," IEEE Trans. Power Syst., vol. 9, no. 4, pp. 1744-1751, 1994.

[3] N. K. Dewangan, H. S. Sachdev, and B. Shaw, "An Analysis of Transient Response of Isolated Small Hydropower Plant with Application of CRPSO Optimized PID Controller," International Journal of Pure and Applied Mathematics, vol. 114, no. 9, pp. 137-145, 2017.

[4] L. A. L. Tenorio, "Hydro Turbine and Governor Modelling: Electric - Hydraulic Interaction," Norwegian University of Science and Technology, Master Thesis, 2010. $\quad$ https://daim.idi.ntnu.no/masteroppgaver/005/5451/masteroppgave.pdf (accessed on 4/26/2018)

[5] P. Kundur, N.J. Balu, and M.G. Lauby, Power system stability and control. Vol. 7. 1994: McGraw-hill New York.

[6] K. Kim and R. C. Schaefer, "Tuning a PID controller for a digital excitation control system," Conf. Rec. 2004 Annu. Pulp Pap. Ind. Tech. Conf. (IEEE Cat. No.04CH37523), vol. 41, no. 2, pp. 485-492, 2004.

[7] F. P. De Melo and R. J. Koessler, "Hydraulic Turbine and Turbine Control Models for System Dynamic Studies," Trans. Power Syst., vol. 7, no. 1, pp. 167-179, 1992.

[8] S. Syan and G. R. Biswal, "Frequency control of an isolated hydro power plant using artificial intelligence," 2015 IEEE Work. Comput. Intell. Theor. Appl. Futur. Dir., pp. 1-5, 2015. DOI: 10.1109/WCI.2015.7495537

[9] H. Goyal, T. S. Bhatti, and D. P. Kothari, "A novel technique proposed for automatic control of small hydro power plants," International Journal of Global Energy Issues, vol. 24, pp. 29-46, 2005. DOI: 10.1504/IJGEI.2005.007076

[10]M. G. Molina and M. Pacas, "Improved power conditioning system of micro-hydro power plant for distributed generation applications," 2010 IEEE Int. Conf. Ind. Technol., pp. 1733-1738, 2010. DOI: 10.1109/ICIT.2010.5472461 
[11]G. A. Aggidis, E. Luchinskaya, R. Rothschild, and D. C. Howard, "The costs of small-scale hydro power production: Impact on the development of existing potential," Renew. Energy, vol. 35, no. 12, pp. 2632-2638, 2010

[12] R. Bhoi and D. S. M. Ali, "Potential of Hydro Power Plant in India and its Impact on Environment," Int. J. Eng. Trends Technol., vol. 10, no. 3, pp. 114-119, 2014.

[13]T. Abbasi and S. A. Abbasi, "Small hydro and the environmental implications of its extensive utilization," Renew. Sustain. Energy Rev., vol. 15, no. 4, pp. 2134-2143, 2011.

[14]J. R. Nayak, B. Shaw, and B. K. Shahu, "Load frequency control of hydro-thermal power system using fuzzy PID controller optimized by hybrid DECRPSO algorithm," International Journal of Pure and Applied Mathematics, vol. 114, no. 9, pp. 147-155, 2017.

[15]H. Shareef, A. A. Ibrahim, and A. H. Mutlag, "Lightning search algorithm," Appl. Soft Comput. J., vol. 36, pp. 315-333, 2015.

[16]N. I. Petrov, G. N. Petrova, and F. D. Alessandro, "Quantification of the Probability of Lightning Strikes to Structures Using a Fractal Approach," IEEE Transactions on Dielectrics and Electrical Insulation, vol. 10, no. 4, pp. 641-654, 2003. DOI: 10.1109/TDEI.2003.1219649

[17]H. R. Tizhoosh, "Opposition-Based Learning: A New Scheme for Machine Intelligence," Comput. Intell. Model. Control Autom. 2005 Int. Conf. Intell. Agents, Web Technol. Internet Commer. Int. Conf., vol. 1, pp. 695-701, 2005.

[18]C. K. Shiva and V. Mukherjee, "A novel quasi-oppositional harmony search algorithm for AGC optimization of three-area multi-unit power system after deregulation," Eng. Sci. Technol. an Int. J., vol. 19, no. 1, pp. 395-420, 2016.

[19]J. R. Nayak, B. Shaw, and B. K. Sahu, "Application of adaptive-SOS (ASOS) algorithm based interval type-2 fuzzy-PID controller with derivative filter for automatic generation control of an interconnected power system," Int. J. Engineering Science and Technology, 2018. DOI: 10.1016/j.jestch.2018.03.010.

[20]J.R. Nayak, B. Shaw, S. Das, and B.K. Sahu, "Design of MI fuzzy PID controller optimized by Modified Group Hunting Search algorithm for interconnected power system,” Microsyst. Technol., 2018. DOI: 10.1007/s00542-018-3788-3.

Article copyright: (C) 2018 Shashikant and Binod Shaw. This is an open access article distributed under the terms of the Creative Commons Attribution 4.0 International License, which permits unrestricted use and distribution provided the original author and source are credited. 